\title{
Corn Water Variables Assessments from Earth Observation Data in the São Paulo State, Southeast Brazil
}

\author{
Antônio Heriberto de Castro Teixeira ${ }^{1}$, Fernando Braz Tangerino Hernandez ${ }^{2}$, Ricardo Guimarães Andrade ${ }^{1}$, \\ Janice Freitas Leivas ${ }^{1}$, Daniel de Castro Victoria ${ }^{1}$ and Edson Luis Bolfe ${ }^{1}$ \\ 1. Department of Geosciences, Embrapa Satellite Monitoring, Campinas, São Paulo, 13070-115, Brazil \\ 2. Department of Hydrology, São Paulo State University, Ilha Solteira, São Paulo, 15.385-000 São Paulo, Brazil
}

\begin{abstract}
Landsat satellite images and agrometeorological data were used together for modelling the crop coefficient $\left(\mathrm{K}_{\mathrm{c}}\right)$ in irrigation pivots composed by a mixture of corn hybrids from a commercial farm for grains and silage, located at the northwestern side of São Paulo state, Brazil. After developing relationships between $\mathrm{K}_{\mathrm{c}}$ and the accumulated degree-days $\left(\mathrm{DD}_{\mathrm{ac}}\right)$ and having yield data for 2012 available, they were applied in the whole state, to upscale the crop water variables, during the GS (growing seasons) of a second-harvest crop from March to August. Spatial thermohydrological differences among the main corn growing regions were clear. The largest CWP (crop water productivity) values and SD (standard deviations) were for Itapetininga with an average value of $1.60 \pm 0.43 \mathrm{~kg} \mathrm{~m}^{-3}$, while the lowest ones were for Presidente Prudente $\left(0.81 \pm 0.21 \mathrm{~kg} \mathrm{~m}^{-3}\right)$. As corn is important for these growing regions, being inside of the priorities from the Brazilian Ministry of Agriculture, these results should be considered for a rational exploration, including both, irrigation and rainfed conditions, as the actual water scarcity can bring much competition with other non-agricultural sectors.
\end{abstract}

Key words: Crop coefficient, degree-days, WI (water indicator), crop water productivity.

\section{Introduction}

In the Southeast region of Brazil, one of the main crops is corn (Zea mays L.), which has been realized in two times of the year. The first-harvest crop is sowed between October and November, at the start of the rainy seasons, while the second-harvest sown happens from February to March. In both cases, the purposes are either for human consumption or for animal feed.

Weather parameters influence the corn photosynthetic activity and water fluxes. Soil moisture is important to maintain yield at optimum levels, as the water deficit is the main climatic risk for the second-harvest crop, being attenuated at high-altitude

Corresponding author: Antônio Heriberto de Castro Teixeira, Ph.D., main research field: environmental sciences. E-mail: heriberto.teixeira@embrapa.br. areas [1]. Water stress can affect the vegetative growth, crop development and the physiological processes, reducing yield, which, in turn, is a function of evapotranspiration [2-3].

Corn crop growing regions in the Brazilian Southeast are inside of the priority contexts from the national Ministry of Agriculture, with emphasis on the development and applications of Earth observations to assess agricultural climatic risks, based on agrometeorological indicators. Thus, knowledge about corn water variables on a large scale in Brazil is important for potential adaptations to extreme climate conditions and land use changes, when aiming the rational management of the water resources.

Evapotranspiration is critically important because it is essential for agricultural production, and its increase means less water available for ecological and human uses in river basins. Distinctions are made between 
reference $\left(\mathrm{ET}_{0}\right)$, potential $\left(\mathrm{ET}_{\mathrm{p}}\right)$ and actual $(\mathrm{ET})$ evapotranspiration [4]. $\mathrm{ET}_{0}$ is the water flux from a reference surface, not a shortage of water, which in this paper and in standard practice is considered a hypothetical grass surface with specific characteristics. $\mathrm{ET}_{\mathrm{p}}$ refers to the water flux from crops that are grown in large fields under optimum soil moisture, excellent management and environmental conditions, achieving full production. ET is the real water flux occurring from vegetation in a specific situation involving all environmental conditions. Due to sub-optimal crop management and environmental constraints that affect plant growth and limit the water fluxes, ET is frequently smaller than $\mathrm{ET}_{\mathrm{p}}$ in agricultural crops. In this paper, $\mathrm{ET}_{\mathrm{p}}$ is considering the corn WR (water requirements).

Field measurements of water variables on a large scale are missing and using tools like remote sensing and/or GIS (geographic information systems) [5], excluding the need of quantifying complex hydrological processes and being a useful way for determining and mapping these variables, can solve this problem. The suitability of combining Landsat measurements and GIS was confirmed when assessing vineyard water requirements in commercial table grapes in the semiarid region of Brazil [6].

For the current study, due to its applicability, the SAFER (simple algorithm for evapotranspiration retrieving) algorithm [5, 7] was used with Landsat images to estimate the crop coefficient $\left(\mathrm{K}_{\mathrm{c}}\right)$ in irrigated pivots with corn crops, located in the norhwestern side of São Paulo state, Brazil. To upscale the corn water variables to the whole state, specific relations for grains and silage between $K_{c}$, and the accumulated degree-days $\left(\mathrm{DD}_{\mathrm{ac}}\right)$ were elaborated and applied with weather data, similarly to what was done for table and wine grapes in the Brazilian Northeast [8].

CWP is analysed as the ratio of the actual corn yield $\left(\mathrm{Y}_{\mathrm{a}}\right)$ to the WR for a growing season in the main growing regions of the São Paulo state. In water-limited environments, the challenge is to make improvements on CWP through optimized management practices [9]. Many ways of raising CWP in agriculture are possible for both irrigated and rainfed crops [10].

CWP values have been summarized for irrigated crops (wheat, rice, cotton and corn) [11], for dry land crops [12], and for rainfed crops [13]. Examples of field measurements to quantify CWP in oats, sunflower, legumes and potato have been given for the semi-arid conditions of Mongolia [14]. Also under semi-arid conditions, but in Northern India, CWP has been quantified in oilseed crops [9]. Considering the large-scale water variables acquirements by satellite images and GIS, CWP mapping, can be found for several agro-ecosystems $[5,11,15]$.

Despite these site specific and large-scale studies, research is still needed further evaluating the crop water productivity, especially for operational applications in different agro-ecosystems with high temporal and spatial thermohydrological inhomogeneity. The objective of the current research was to combine geo-technologies for modeling the corn water variables on a large scale, including both commercial goals, grains and silage production in the São Paulo state, Brazil. The models were first elaborated with Landsat images and weather data in irrigated pivots of a reference farm in the northwesten side of São Paulo and later up scaling these variables with a GIS. Emphases are given in CWP analyzes inside the main growing regions aiming subsidize improvements on the water use, under the conditions of climate and land use change which has been responsible for severe water scarcity.

\section{Materials}

Fig. 1 presents the location of the São Paulo state in the Southeast Brazil, its main corn growing regions, the agrometeorological stations, and the center-pivots, where the Landsat images were used for water variables modelling.

Data during 2010 from an agrometeorological station 


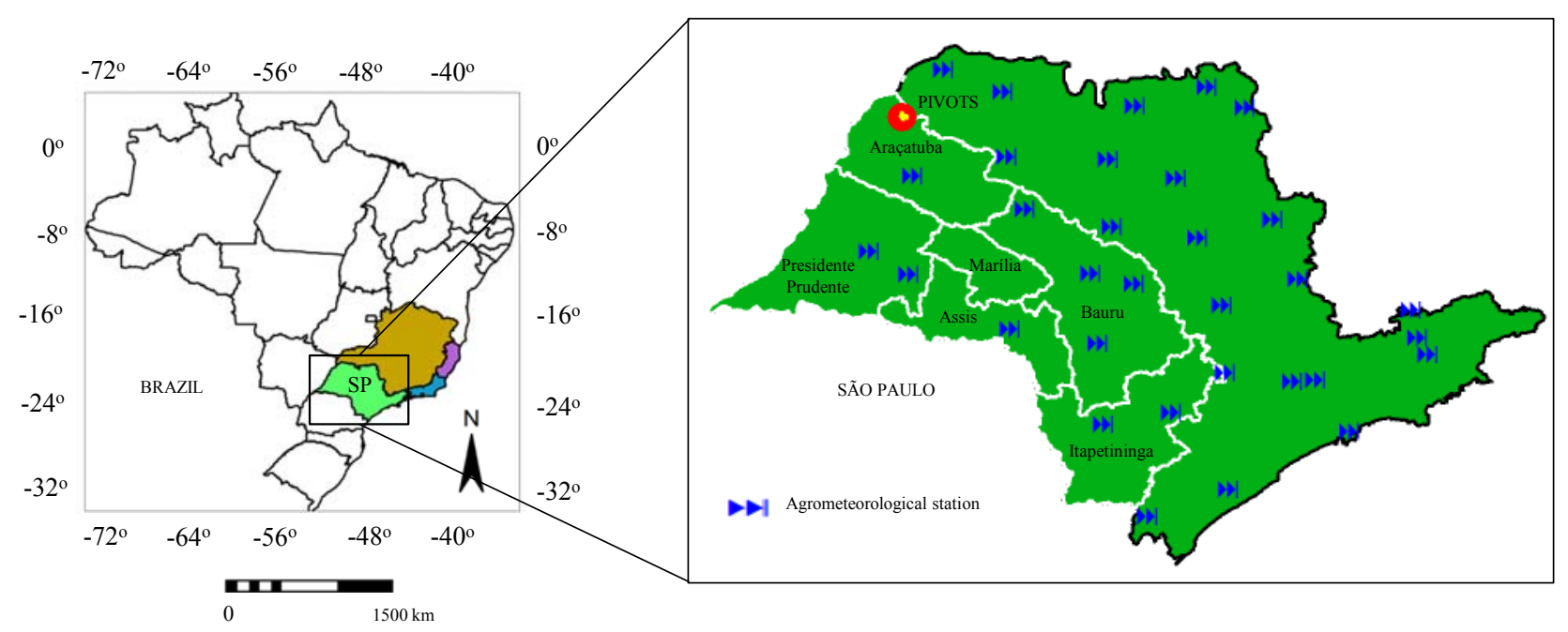

Fig. 1 Location of the São Paulo state, the main corn growing regions of the state, the agrometeorological stations (arrows), and the corn center-pivots, where the Landsat images were used for corn water variables modelling in the Southeast Brazil.

close to the irrigation pivots were taken for $\mathrm{K}_{\mathrm{c}}$ modelling, together with remote sensing parameters throughout the application of the SAFER algorithm [5, 7]. Landsat 5 images for the days 03/22, 04/07, 04/23, $06 / 10,06 / 26,07 / 12$ and $08 / 29$ were used for this year, together with temporal interpolations covering complete growing seasons in each corn irrigation pivot of the commercial farm.

After developing specific regression equations, which relate $\mathrm{K}_{\mathrm{c}}$ and $\mathrm{DD}_{\mathrm{ac}}$, taking the basal temperature $\left(\mathrm{T}_{\mathrm{b}}\right)$ as $10^{\circ} \mathrm{C}$, the equations were applied together with weather data for the year 2012, from a net of agrometeorological stations from INMET (the national meteorological institute) (Fig. 1). After the weather data interpolations in the entire state, the spatial distribution of the corn water variables for grains and for silage were acquired, latter extracting the main growing regions for CWP analyses.

In the current study, only the visible and the near infrared bands from Landsat 5 were used for $K_{c}$ estimations in the irrigation pivots, being the surface temperature $\left(\mathrm{T}_{\mathrm{S}}\right)$ retrieved as a residual in the radiation balance equation. This technique assured a $30 \mathrm{~m}$ spatial resolution for all water variables [16].

For retrieving surface albedo $\left(\alpha_{0}\right)$, firstly the planetary albedo for each satellite band $\left(\alpha_{p_{\text {band }}}\right)$ was calculated as:

$$
\alpha_{\mathrm{p}_{\text {band }}}=\frac{\mathrm{L}_{\text {band }} \pi \mathrm{d}^{2}}{\mathrm{R}_{\mathrm{a}_{\text {band }}} \cos \varphi}
$$

where $\mathrm{L}_{\mathrm{band}}$ is the spectral radiance for the wavelengths of the band, $d$ is the relative earth-sun distance; $\mathrm{R}_{\mathrm{a}_{\text {band }}}$ is the mean solar irradiance at the top of the atmosphere for each band $\left(\mathrm{Wm}^{-2} \mu \mathrm{m}^{-1}\right)$ and $\varphi$ the solar zenith angle [7].

The planetary albedo for the entire solar spectrum $\left(\alpha_{p}\right)$ is calculated as the total sum of the different narrow-band $\alpha_{p_{\text {band }}}$ values according to weights for each band ( $\left.w_{\text {band }}\right)$.

$$
\alpha_{\mathrm{p}}=\sum \mathrm{w}_{\text {band }} \alpha_{\mathrm{p}_{\text {band }}}
$$

The weights for the different bands are computed as the ratio of the amount of the incoming shortwave radiation from the sun in a particular band and the sum of incoming shortwave radiation for all the bands at the top of the atmosphere.

The daily $\alpha_{0}$ values were obtained according to [7]:

$$
\alpha_{0}=a \alpha_{p}+b
$$

where $\mathrm{a}$ and $\mathrm{b}$ are regression coefficients, which for $\mathrm{a}$ 24-hour period was considered as 1.70 and 0.13 , obtained from field and satellites measurements [7, 16-17].

The NDVI (normalized difference vegetation index) is an indicator related to the land cover obtained from 
satellite images as:

$$
\mathrm{NDVI}=\frac{\alpha_{\mathrm{p}_{(\mathrm{NIR})}}-\alpha_{\mathrm{p}_{(\mathrm{RED})}}}{\alpha_{\mathrm{p}_{(\mathrm{NIR})}}+\alpha_{\mathrm{p}_{(\mathrm{RED})}}}
$$

where $\alpha_{\mathrm{p}_{(\mathrm{NIR})}}$ and $\alpha_{\mathrm{p}_{(\mathrm{RED})}}$ represent the planetary albedo over the ranges of wavelengths in the near infrared (NIR) and red (RED) regions of the solar spectrum, respectively.

$\mathrm{T}_{\mathrm{S}}$ was estimated following [16]:

$$
\mathrm{T}_{\mathrm{S}}=\sqrt[4]{\frac{\mathrm{R}_{\mathrm{G}}-\alpha_{0} \mathrm{R}_{\mathrm{G}}+\varepsilon_{\mathrm{A}} \sigma \mathrm{T}_{\mathrm{a}}^{4}-\mathrm{R}_{\mathrm{n}}}{\varepsilon_{\mathrm{S}} \sigma}}
$$

where $\mathrm{R}_{\mathrm{G}}$ and $\mathrm{T}_{\mathrm{a}}$ are the 24-hour values of global solar radiation and air temperature from the agrometeorological station close to the irrigation pivots, $R_{n}$ is the daily net radiation spatially obtained, $\varepsilon_{\mathrm{A}}$ and $\varepsilon_{\mathrm{S}}$ are, respectively, atmospheric and surface emissivities, and $\sigma$ is the Stefan-Boltzmann constant $\left(5.67 \times 10^{-8} \mathrm{~W} \mathrm{~m}^{-2} \mathrm{~K}^{-4}\right)$.

Following $[7,16] \varepsilon_{\mathrm{A}}$ and $\varepsilon_{\mathrm{S}}$ were calculated as:

$$
\begin{gathered}
\varepsilon_{\mathrm{A}}=\mathrm{a}_{\mathrm{A}}\left(-\ln \tau_{\mathrm{sw}}\right)^{\mathrm{b}_{\mathrm{A}}} \\
\varepsilon_{\mathrm{S}}=\mathrm{a}_{\mathrm{S}} \ln \mathrm{NDVI}+\mathrm{b}_{\mathrm{S}}
\end{gathered}
$$

where $\tau_{\mathrm{sw}}$ is the short-wave atmospheric transmissivity defined as the ratio of $R_{G}$ to the incident solar radiation at the top of atmosphere, and $\mathrm{a}_{\mathrm{A}}, \mathrm{b}_{\mathrm{A}}$, as and $b_{S}$ are regressions coefficients which, from [7], were considered, respectively, $0.06,1.00,0.94$ e 0.10 .

The Slob equation was used for $\mathrm{R}_{\mathrm{n}}[7,16]$ :

$$
\mathrm{R}_{\mathrm{n}}=\left(1-\alpha_{0}\right) \mathrm{R}_{\mathrm{G}}-\mathrm{a}_{\mathrm{L}} \tau_{\mathrm{sw}}
$$

Because of the thermal influence on longwave radiation via the Stephan Boltzmann equation, previous study investigated whether the variations of the $a_{L}$ coefficient from Eq. 8 could be explained by variations in 24-hour $T_{a}$ values [17]:

$$
\mathrm{a}_{\mathrm{L}}=\mathrm{cT}_{\mathrm{a}}-\mathrm{d}
$$

where $\mathrm{c}$ and $\mathrm{d}$ are regression coefficients found to be 6.99 and 39.93 [7, 16-17].
Having calculated the SAFER input parameters from Landsat images, the $\mathrm{ET} / \mathrm{ET}_{0}$ ratio was acquired:

$$
\frac{E T}{E T_{0}}=\exp \left[e+f\left(\frac{T_{S}}{\alpha_{0} \text { NDVI }}\right)\right]
$$

where $\mathrm{e}$ and $\mathrm{f}$ are the regressions coefficients, being 1.0 and -0.008 , respectively, for the São Paulo Northwestern conditions [18].

The average $\mathrm{ET} / \mathrm{ET}_{0}$ values in the well-irrigated buffered areas of the pivots gave $\mathrm{K}_{\mathrm{c}}$, allowing modelling their values with $\mathrm{DD}_{\mathrm{ac}}$ :

$$
\mathrm{K}_{\mathrm{c}}=\mathrm{gDD}_{\mathrm{ac}}{ }^{2}+\mathrm{hDD}_{\mathrm{ac}}+\mathrm{i}
$$

where $\mathrm{g}, \mathrm{h}$ and $\mathrm{i}$ are specific regression constants determined in the current research by the coupled use of satellite and weather measurements [6].

With the availability of the weather data from the agrometeorological stations represented by the arrows in Fig. 1, the spatial distribution of corn water requirements WR was then gridded, considering ET under potential conditions $[8,19]$ in the entire São Paulo state:

$$
\mathrm{WR}=\mathrm{K}_{\mathrm{c}} \mathrm{ET}_{0}
$$

The spatial WR values together with those for precipitation $(\mathrm{P})$ allowed the application of a water index for the moisture delimitation in the São Paulo state, during the growing season of the second-harvest corn crop $[8,19]$.

$$
\mathrm{WI}=\frac{\mathrm{P}}{\mathrm{WR}}
$$

The indicator represented by Eq. 13 enables the characterization of the climatic water component, taking into account the input and output of natural water from and to the crop under optimum agronomic conditions, indicating the potential moisture availability in the root zones $[8,19]$.

With data on actual yield $\left(\mathrm{Y}_{\mathrm{a}}\right)$ from the IBGS (Geographic and Statistics Brazilian Institute) and layering their values with the WR grids, the spatial distribution of CWP could be determined under 
optimum soil moisture conditions in the main corn growing regions of the São Paulo state:

$$
\mathrm{CWP}=\frac{\mathrm{Y}_{\mathrm{a}}}{\mathrm{WR}}
$$

\section{Results and Discussion}

Fig. 2 shows the spatial distribution of the ET/ET 0 values involving the reference commercial farm, which is located in the northwestern part of São Paulo state, Brazilian Southeast region, including irrigated areas, natural vegetation and water bodies.

Clearly, one can distinguish irrigation pivots from the natural vegetation by their higher $\mathrm{ET} / \mathrm{ET}_{0}$ values, with some pixels close to 1.40 . The farm has pivots with corn, soybeans, beans and sugar cane; however, to relate $\mathrm{K}_{\mathrm{c}}$ as a function of the accumulated degree-days $\left(\mathrm{DD}_{\mathrm{ac}}\right)$ for corn crop, the values of $\mathrm{ET} / \mathrm{ET}_{0}$ from SAFER results inside its irrigation pivots were used. It were considered the average pixel values inside buffered areas of six irrigation pivots for grains $(G)$ and eight for silage (S), under optimum soil moisture conditions and the basal temperature $\left(\mathrm{T}_{\mathrm{b}}\right)$ of $10{ }^{\circ} \mathrm{C}$ (Fig. 3).

$\mathrm{K}_{\mathrm{c}}$, at different corn crop stages, was between 0.3 and 1.2. This range is in agreement with the values in Colorado (USA) [20] and with those of the standard work from [4], which justified confidence in using the SAFER algorithm with acceptable accuracy and without the thermal band.

In the current research, the equations from Fig. 3 were applied to estimate the large-scale WR values, which together with yield data, were considered key-parameters for water productivity assessments. The advantage of this methodology is the possibility of upscaling $\mathrm{K}_{\mathrm{c}}$ values to different thermal conditions [10]. This is important for upscaling WR to different scenarios, eliminating the subjectivity of the crop stage characterization in situations of year-to-year air temperature variation, which will affect plant phenology [19].

Eq. 12 was applied to the grids of $\mathrm{ET}_{0}$ in the entire Sao Paulo state (Fig. 4), being the main corn growing areas later extracted for WR analyses, considering a second-harvest GS from March to August.

Taking into account the entire Sao Paulo state, there was a gradient in the WR values, with the lowest ones from the coastal side, bellow $300 \mathrm{~mm} \mathrm{GS}^{-1}$, increasing toward the west side of the, where they are higher than

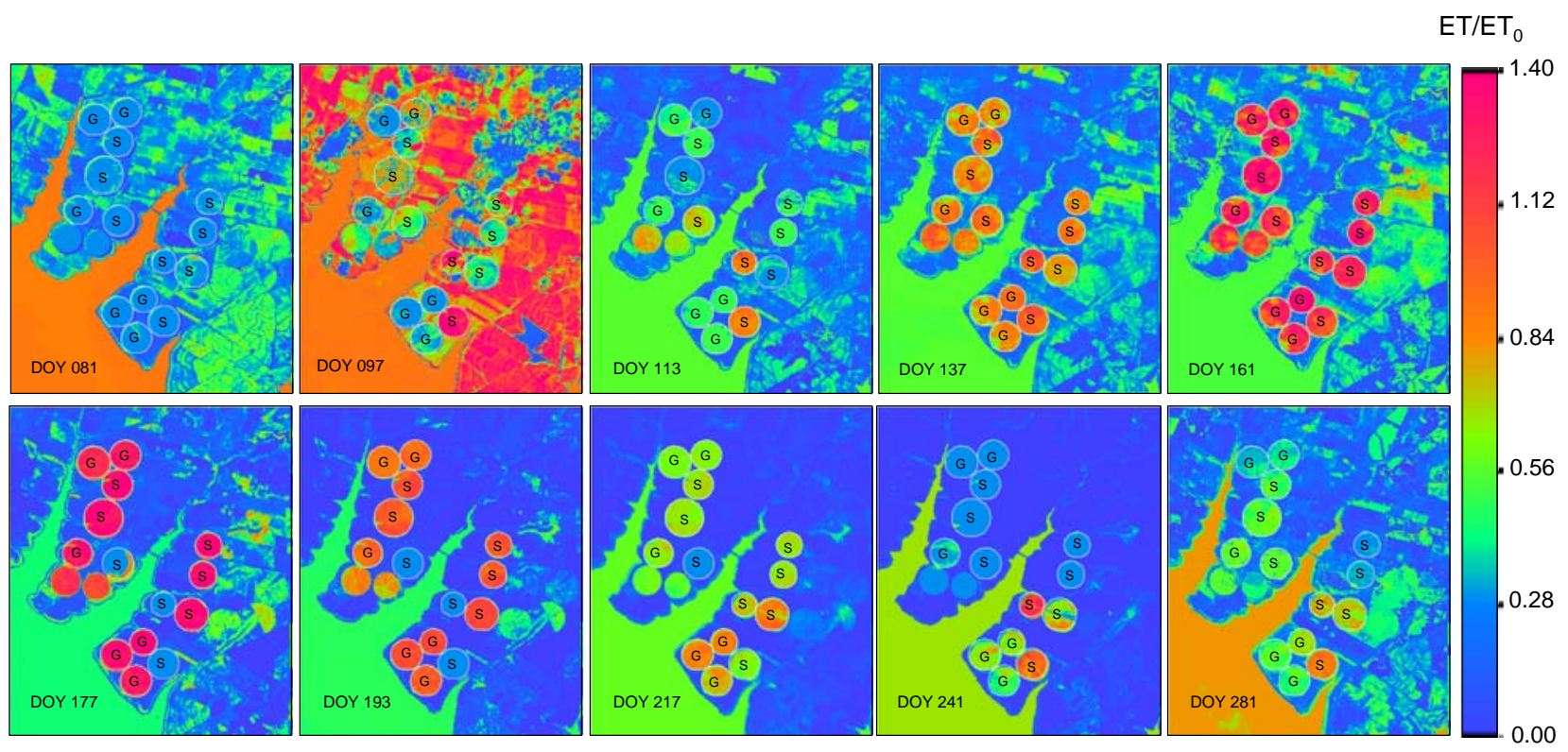

Fig. 2 Spatial distribution of the ET/ET $\mathbf{E T}_{0}$ ratio in the reference commercial farm, located at the northwestern side of the São Paulo state, Brazilian Southeast region. DOY means Days of the Year and the letters G and S are corn irrigation pivots for grain and for silage, respectively. 


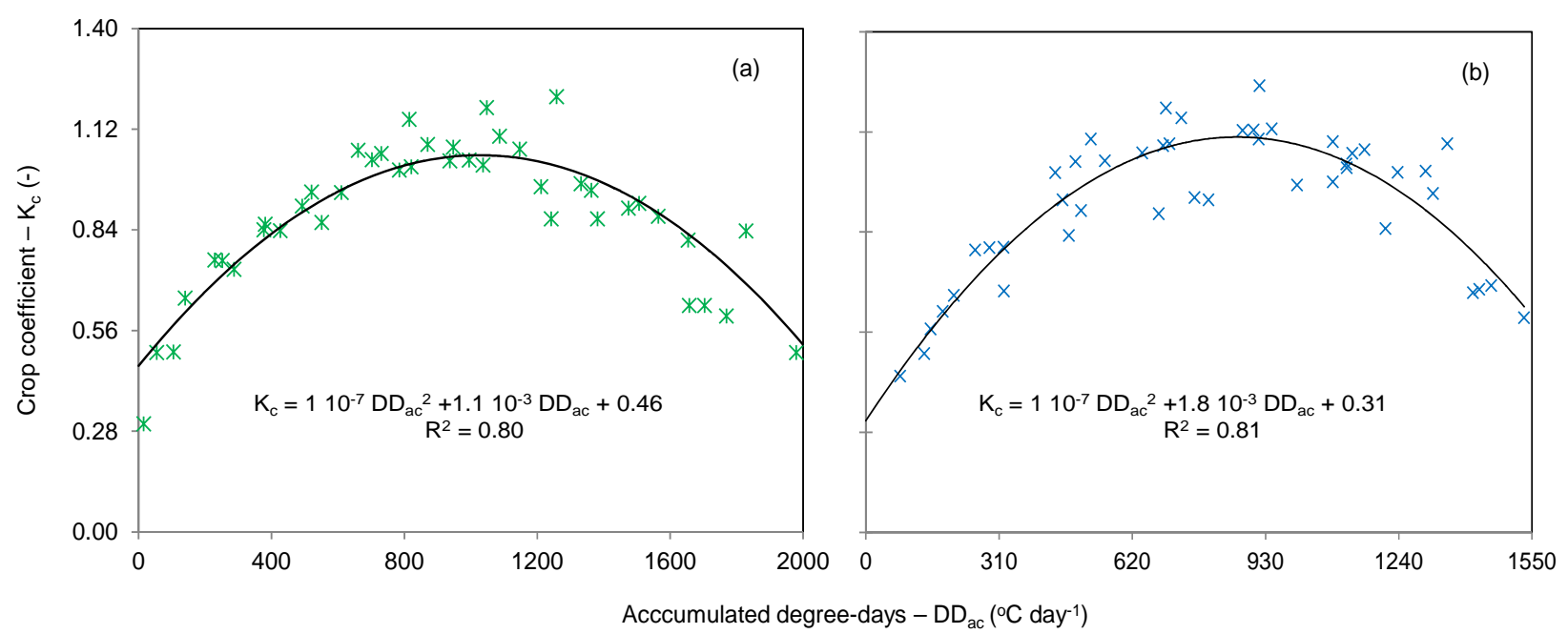

Fig. 3 Relations between the crop coefficient $\left(K_{c}\right)$ and the accumulated degree-days $\left(D_{a c}\right)$ for corn crop in the northwestern side of the Sao Paulo State, Southeast Brazil: (a) grains; (b) silage. A basal temperature $\left(\mathrm{T}_{\mathrm{b}}\right)$ of $10^{\circ} \mathrm{C}$ is considered.

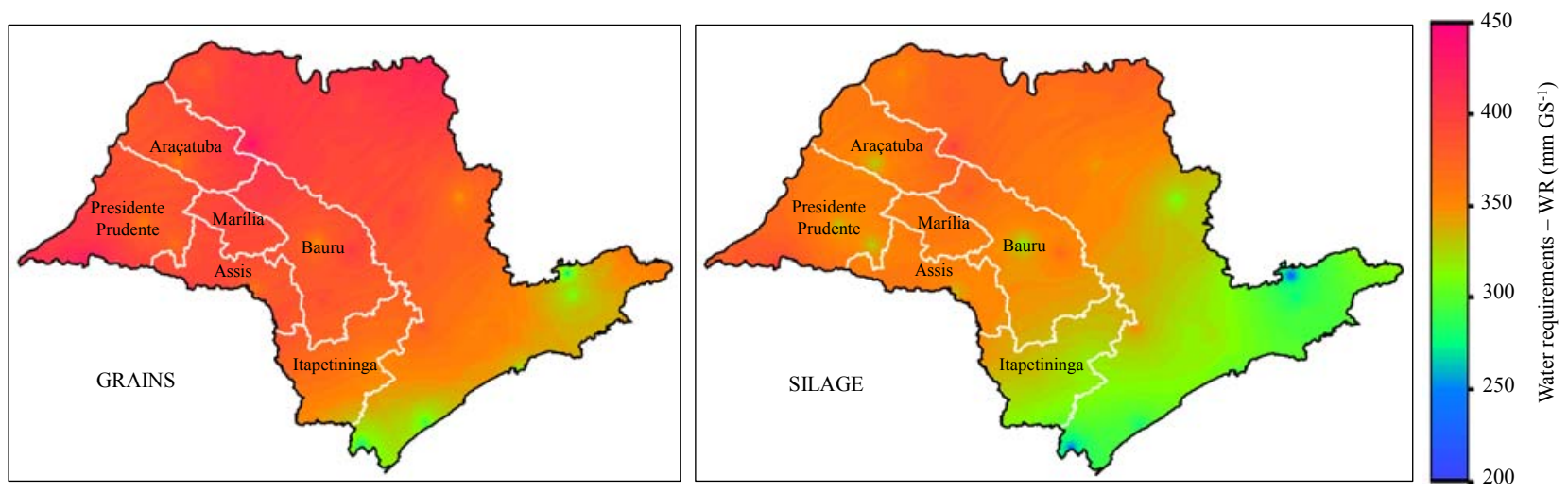

Fig. 4 Spatial distribution of the WR for a second-harvest corn GS, from March to August 2012, in the São Paulo state, Southeast Brazil, highlighting the main growing regions.

$400 \mathrm{~mm} \mathrm{GS}^{-1}$, with the ones for grains larger than those for silage production. The larger values for grains than for silage are due to the different GS lengths, which were, on average, 160 and 120 days, respectively, and this is bound to affect the water productivity components depending mainly on the rainfall conditions along the crop stages. The coastal weather conditions seem to be a good option for corn crop expansion, in situations of water competition among different water users [10].

The main corn growing regions were extracted from Sao Paulo state, and the WR mean pixel values for a second-harvest GS together with the SD were analyzed (Fig. 5).
For grains, it can be seen from Fig. 5a, that Presidente Prudente is highlighted by the highest water demand, with maximums $\mathrm{WR}_{\mathrm{GS}}$ around $440 \mathrm{~mm}$ $\mathrm{GS}^{-1}$, while the minimums ones go to Itapetininga, $325 \mathrm{~mm} \mathrm{GS}^{-1}$. The silage corresponding values (Fig. 5b) were around 405 and $295 \mathrm{~mm} \mathrm{GS}^{-1}$. Regarding the spatial variations, and considering both, grains and silage production, the highest and the lowest SD are for President Prudente and Marília, respectively around 11.5 and $3.0 \mathrm{~mm} \mathrm{GS}^{-1}$. For all growing regions, WR values for silage represented $90 \%$ from those for grains, what is relevant to be considered when analyzing the physical and economic values of water productivity. 
From the one hand, as a direct relation between crop water consumption and crop yield is expected [21], as a first guess, corn crop should be stimulated in President Prudente to attain high production levels. From the other hand, if there is no strong reduction on yield, as recently São Paulo has experienced severe water scarcity, the growing regions with lower WR such as Itapetininga should have more attention, when aiming the better use of the water resources. In this last case, more research for improving CWP should be carried out, because the CWP variability is also due to the crop and water management practices [22].

WR in the current paper is considered as ET rates if the crop is under optimum soil moisture conditions. In this case, the mean daily rates should be between 2.3 and $3.0 \mathrm{~mm} \mathrm{day}^{-1}$ among the main growing regions, considering both situations grains and silage goals. In the Northwest of China, field measurements and modeling, returned higher corn ET daily rates,

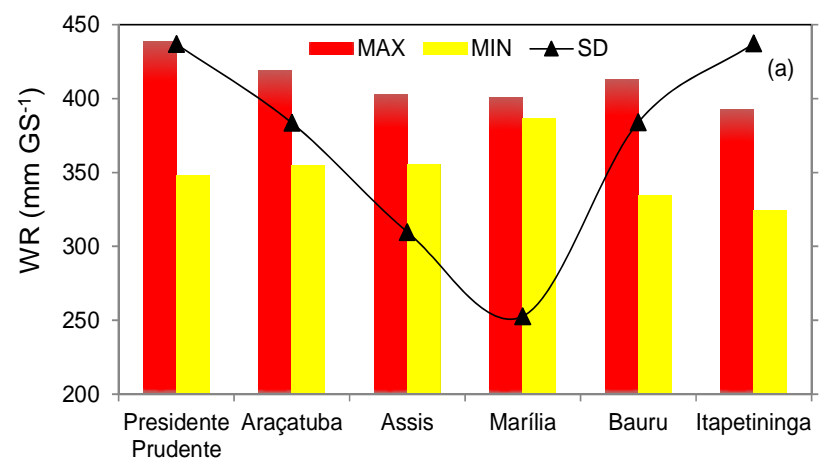

averaging $3.5 \mathrm{~mm} \mathrm{day}^{-1}$ [23]. The main reason for the lower values in São Paulo could be explained by the inhomogeneity of the atmospheric demand among these regions, against those from the uniform irrigated cornfield in China.

Fig. 6 presents the spatial distribution of the WI for grains and silage considering a second-harvest corn GS from March to August in the São Paulo state, Southeast Brazil, highlighting the main growing regions.

WI around 1.00 implies the feasibility for rainfed corn crop, while those much higher may indicate problems due to moisture excess. Low WI values mean natural water deficiencies and can quantify the degree of irrigation needs. The northwestern side of the São Paulo presented the largest area under natural dryness conditions, bellow 1.00 , bringing the need of supplementary irrigation for both grains and silage productions. On the other hand, WI higher than 1.50

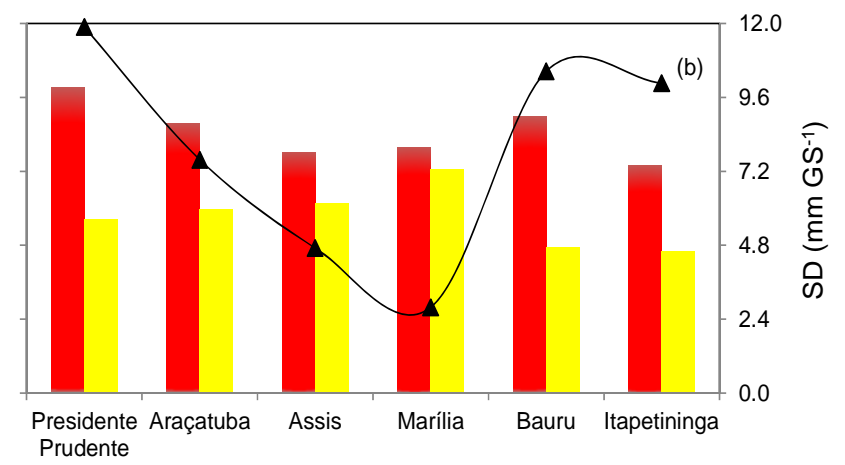

Corn growing regions

Fig. 5 WR together with the SD, for a second-harvest corn GS, from March to August 2012, in the main growing regions of the São Paulo state, Southeast Brazil: (a) grains; (b) silage.
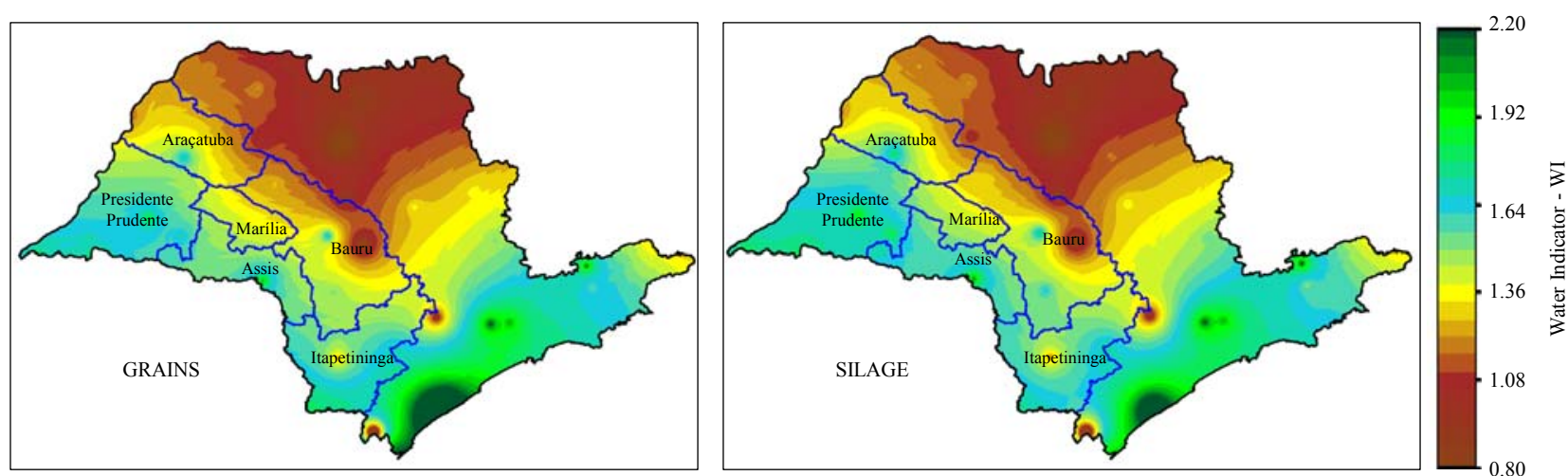

Fig. 6 Spatial distribution of the WI for a second-harvest corn GS, from March to August 2012, in the São Paulo state, Southeast Brazil, highlighting the main growing regions. 
happened in the southeastern and southwestern sides of the State, meaning that rainfall satisfy the water requirements. These last conditions included the main corn crop growing regions. Only a small area of the southeastern side, outside these growing regions, with WI above 2.00, should present problems of water excess for corn crop.

Fig. 7 shows the average WI pixel values in the corn growing regions for grains and for silage, together with the SD, considering the second-harvest crop from March to August in the São Paulo state, Southeast Brazil.

The highest WI values, around 1.60 were found in Presidente Prudente, indicating much natural corn water availability for both grains and silage. On the other hand, the lowest ones, around 1.30, were verified in Bauru and Araçatuba. Considering the spatial variation, the largest SD values were in Bauru and the lowest ones in Marília. These results call more attention for supplementary irrigation needs in Bauru and higher probability of drainage rates in Presidente Prudente depending on the soil types. To reduce these drainage rates, practices of mulching could be used [23] to improve crop water productivity CWP.

Data on corn CP for grains in the year 2012 in the São Paulo state, at the municipality scale, were obtained from the IBGS. Layering them with WR maps, gave the opportunity of analyzing the spatial CWP in the main growing regions by applying Eq. 14 . The CWP spatial distribution together with the average pixel values and SD for each of the main corn growing regions is presented in Fig. 8.

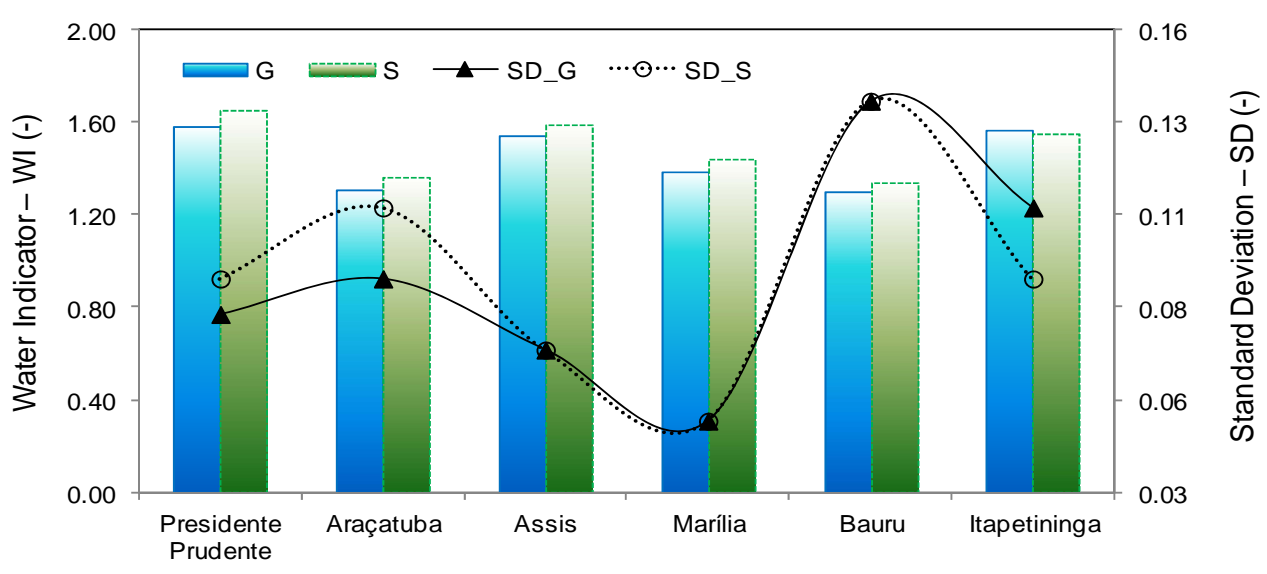

Corn growing regions

Fig. 7 Average pixel values for the WI together with the SD, for a second-harvest corn GS, considering grains (G) and silage (S) production, in the main growing regions of the São Paulo state, Southeast Brazil.

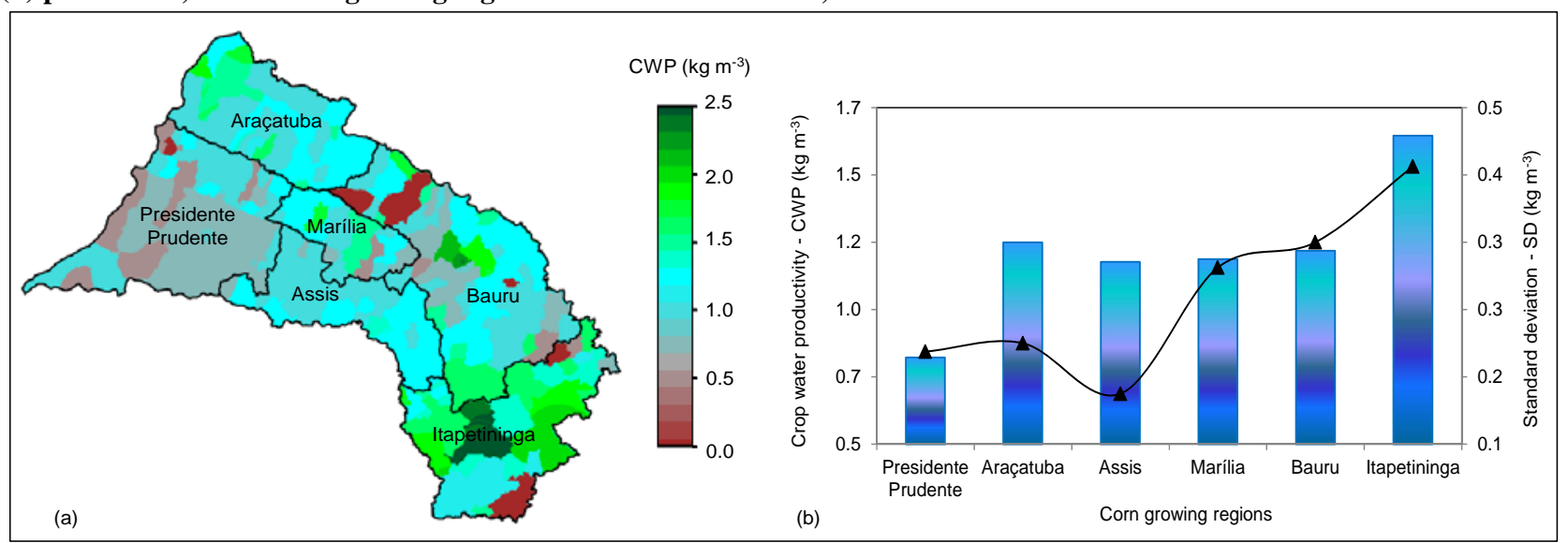

Fig. 8 CWP of corn for grains in the main growing regions of the São Paulo state, Southeast Brazil: (a) spatial distribution; (b) average pixel values and SD. 

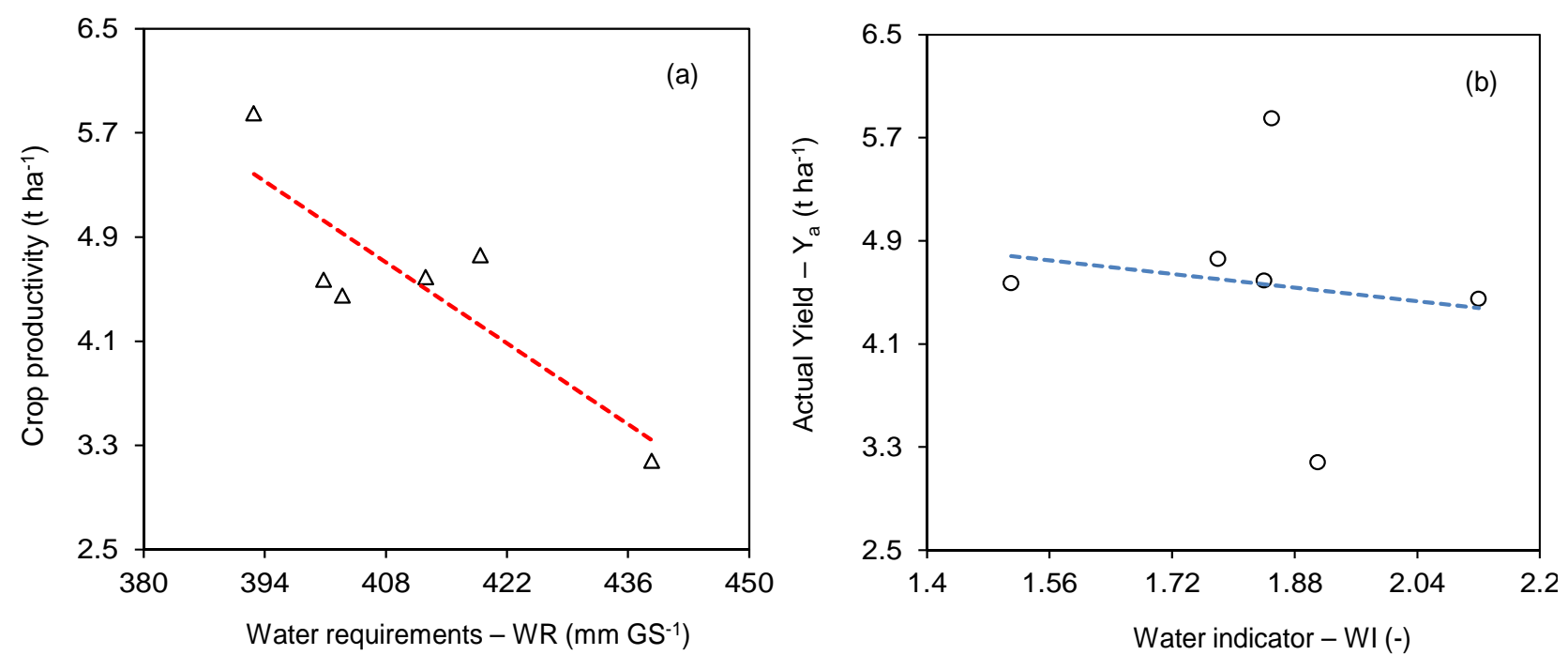

Fig. 9 Relationships between corn CP with water productivity parameters in the main growing regions of the São Paulo state, Brazilian Southeast: (a) with the WR; (b) with the WI.

According to Fig. 8a, CWP spatial differences among the main corn crop growing regions in São Paulo are clear, with the lowest values in the southwestern side of the State. The largest CWP and SD values are for Itapetinga with an average of $1.60 \pm$ $0.43 \mathrm{~kg} \mathrm{~m}^{-3}$, while the lowest ones are for Presidente Prudente, with an average of $0.81 \pm 0.21 \mathrm{~kg} \mathrm{~m}^{-3}$ (Fig. $8 \mathrm{~b})$. On the one hand, comparing the CWP values with those for WI (Fig. 6-8), CWP differences between these growing regions could not be attributed to soil moisture conditions. On the other hand, CWP values were inversely related to WR, what can be seen comparing Fig. 8 with Figs. 4-5 what and shown in Eq. 14.

To analyze how corn CP was related to WR and WI in the main corn growing regions, Fig. 9 was built taking their average values.

According to Fig. 9, there was a good inverse relation between $\mathrm{CP}$ and $\mathrm{WR}$, while with WI there was no consistent trend. Following the direct relation between WR and CWP [21], one could affirm erroneously that the best region for stimulating corn crop growth could be President Prudente. However, by the CWP analyses and considering the actual water scarcity scenarios, the most rational corn crop expansion should be in the growing region of Itapetininga.
Although Presidente Prudente presenting the largest WI values, indicating good rainfall provision, WR values are high and the main reason for the low CWP should be percolations, with the water drained away from the root zones or the crop managements are poor. On the other hand, WI in Itapetininga is high and WR is lower, favoring CWP, what will contribute to a lower use of the water resources, this being a very important aspect in situations of water scarcity scenarios.

In the corn growing regions of São Paulo state, once water is not a limiting factor, corn CWP values are higher than those for wheat and rice [11], which were inside a range from 0.5 to $1.5 \mathrm{~kg} \mathrm{~m}^{-3}$. Having in mind the importance for human and animal feed, mainly in rural environments, the corn water usage should be stimulated with sustainable management, in areas with high CWP in the Southeast Brazil, such as the growing region of Itapetininga.

\section{Conclusions}

Models resulting from the coupled use of satellite images and agrometeorological data, based on the relation between the actual to the reference evapotranspiration and the accumulated degree-days in corn crop, allowed the determination of water indicators in São Paulo state, Brazil, for both grains 
and silage productions. Analyzing the soil moisture conditions by taking account the water input and water requirements, Presidente Prudente, indicating much natural water availability for both commercial goals. However, water requirements for this growing region are high. On the other hand, soil moisture in Itapetininga is large and water requirements are lower, favoring crop water productivity, what will contribute to a lower use of the water resources, this being a very important aspect under water scarcity scenarios. The results of the modelling are useful for improving corn water productivity, according to the commercial interest, considering both, irrigation and rainfed conditions.

\section{Acknowledgements}

To National Council for Scientific and Technological Development (CNPq) and the Brazilian Ministry of Agriculture (MAPA) for the financial support to the project on water productivity. The National Meteorological Institute (INMET) is also acknowledging for providing the weather data for the entire São Paulo state.

\section{References}

[1] Ko, J., and Piccinni, G. 2009. "Corn Yield Responses under Crop Evapotranspiration-based Irrigation Management." Agricultural Water Management 96: 799-808.

[2] Traore, S. B., Carlson, R. E., Pilcher, C. D., and Rice, M. E. 2000. "Bt and Non-Bt Maize Growth and Development as Affected by Temperature and Drought Stress.” Agronomy Journal 92: 1027-35.

[3] Payero, J. O., Melvin, S. R., Irmak, S., and Tarkalson, D. 2006. "Yield Response of Corn to Deficit Irrigation in a Semiarid Climate." Agricultural Water Management 84: 101-12.

[4] Allen, R. G., Pereira, L. S., Raes, D., and Smith, M. 1998. Crop Evapotranspiration: Guidelines for Computing Crop Water Requirements; Food and Agriculture Organization of the United Nations.

[5] Teixeira, A. H. de C., Scherer-Warren, M., Hernandez, F. B. T., Andrade, R. G., and Leivas, J. F. 2013. "Large-Scale Water Productivity Assessments with MODIS Images in a Changing Semi-Arid Environment: A Brazilian Case Study." Remote Sensing 5: 5783-804.
[6] Teixeira, A. H. de C., Hernandez, F. B.T., and Lopes, H. L. 2014a. "Up Scaling Table Grape Water Requirements in the Low-Middle São Francisco River Basin, Brazil." Acta Horticulturae 1038: 655-62.

[7] Teixeira, A. H. de C., Hernandez, F. B. T., Lopes, H. L., Scherer-Warren, M., and Bassoi, L. H. 2014b. A Comparative Study of Techniques for Modeling the Spatiotemporal Distribution of Heat and Moisture Fluxes in Different Agroecosystems in Brazil. In: George G. Petropoulos. (Org.). Remote Sensing of Energy Fluxes and Soil Moisture Content. 1ed.Boca Raton, Florida: CRC Group, Taylor and Francis, 169-91.

[8] Teixeira, A. H. de C., Tonietto, J., Pereira, G. E., Hernandez, F. B. T., Angelotti, F., and Lopes, H. L. 2014c. "Agro-Climatic Suitability Delimitation for Table and Wine Grape Crops under Irrigation Conditions in Northeastern Brazil.” Acta Horticulturae 1038: 277-86.

[9] Adak, T., Kumar, G., Chakravarty, N. V. K., Katiyar, R. K., and Deshmukh, P. S. 2013. "Biomass and Biomass Water Use Efficiency in Oilseed Crop (Brassica Jnceae L.) under Semi-Arid Microenvironments." Biomass and Bioenergy 51: 154-62.

[10] Teixeira, A. H. de C. 2009. Water Productivity Assessments from Field to Large Scale: A Case Study in the Brazilian Semi-Arid Region. LAP Lambert Academic Publishing: Saarbrücken, Germany.

[11] Zwart, S. J., and Bastiaanssen, W. G. M., 2004. "Review of Measured Crop Water Productivity Values for Irrigated Wheat, Rice, Cotton and Maize.” Agricultural Water Management 69: 115-53.

[12] Oweis, T., and Hachum, A., 2006. "Water Harvesting and Supplemental Irrigation for Improved Water Productivity of Dry Farming Systems in West Asia and North Africa." Agricultural Water Management 80: 57-73.

[13] Rockstrom, J., and Barron, J., 2007. "Water Productivity in Rainfed Systems: Overview of Challenges and Analysis of Opportunities in Water Scarcity Prone Savannahs." Irrigation Science 25: 299-311.

[14] Yuan, M., Zhang, L., Gou, F., Su, Z., Spiertz, J. H. J., and Werf, W. van der. 2013. "Assessment of Crop Growth and Water Productivity for Five C3 Species in the Semi-arid Inner Mongolia." Agricultural Water Management 122: 28-38.

[15] Mo, X., Liu, S., Lin, Z., and Guo, R. 2009. "Regional Crop Yield, Water Consumption and Water Use Efficiency and Their Responses to Climate Change in the North China." Agriculture, Ecosystems \& Environment 134: 67-78.

[16] Teixeira, A. H. de C., Hernandez, F. B. T., Andrade, R. G. , Leivas, J. F., and Bolfe, E. L. 2014d. "Energy Balance with Landsat Images in Irrigated Central Pivots with Corn Crop in the São Paulo State, Brazil." In 
Proceedings of SPIE-International Society for Optical Engineering, 9239: 923900-1-923900-10.

[17] Teixeira, A. H. de C., Bastiaanssen, W. G. M., Ahmad, M. D., and Bos, M. G. 2008. "Analysis of Energy Fluxes and Vegetation-Atmosphere Parameters in Irrigated and Natural Ecosystems of Semi-arid Brazil." Journal of Hydrology 362: 110-27.

[18] Hernandez, F. B. T., Teixeira, A. H. de C., Neale, C. M. U., and Taghvaeian, S. 2004. "Determining Large Scale Actual Evapotranspiration Using Agro-Meteorological and Remote Sensing Data in the Northwest of Sao Paulo State, Brazil." Acta Horticulture 1038: 263-70.

[19] Teixeira, A. H. de C., Tonietto, J., Pereira, G. E., and Hernandez, F. B. T. 2014e. "Characterization of the Wine Grape Thermohydrological Conditions in the Tropical Brazilian Growing Region: Long-Term and Future Assessments." ISRN Agronomy: 1-14.

[20] Dejonge, K. C., Ascough, J. C., Andales, A. A., Handen, N. C., Garcia, L. A., and Arabi, M. 2012. "Improving
Evapotranspiration Simulations in the CERES-Maize Model under Limited Irrigation.” Agricultural Water Management 115: 92-103.

[21] Steduto, P., and Albrizio, R., 2005. "Resource-Use Efficiency of Field-Grown Sunflower, Sorghum, Wheat and Chickpea. II. Water Use Efficiency and Comparison with Radiation Use Efficiency." Agricultural and Forest Meteorology 130: 269-81.

[22] Molden, D., Oweis, T., Steduto, P., Kijne, J. W., Hanjra, M. A., and Bindraban, P. S., 2007. Pathways for increasing agricultural water productivity. In: Chapter 7 in Water for Food, Water for Life: A Comprehensive Assessment of Water Management in Agriculture, International Water Management Institute, London, Earthscan, Colombo.

[23] Ding, R., Kang, S., Li, F., Zhang, Y., and Tong, L. 2013. "Evapotranspiration Measurement and Estimation Using Modified Priestly-Taylor Model in an Irrigated Maize Field with Mulching." Agricultural and Forest Meteorology 168: 140-8. 